V.S. Kostyshyn, Dr. Sc. (Tech.), Prof., orcid.org/0000-0001-8606-3931, I. I. Yaremak, Cand. Sc. (Tech.), orcid.org/0000-0002-0698-0367, P. O. Kurliak, Cand. Sc. (Tech.), Assoc. Prof., orcid.org/0000-0001-8113-5211

\title{
CREATION OF OBJECT-ORIENTED MODEL OF CENTRIFUGAL PUMP ON THE BASIS OF ELECTROHYDRODYNAMIC ANALOGY METHOD
}

Purpose. Development of an object-oriented model of a centrifugal pump (CP), which would reflect the constructive features of the structure and processes in it, as well as the simultaneous balance of effort (delivery head and pressure), and flow (flow rates) variables, namely the balance of powers.

Methodology. Applying of the electrohydrodynamic analogy method to the flow diagram of liquid in a centrifugal pump enabled to synthesize the expanded complex equivalent circuit of a $\mathrm{CP}$, spatially combined with its constructive elements.

Findings. The theoretical calculation of the $\mathrm{CP}$ performance characteristics according to its directory data for the entire interval of change in the flow rate duty taking into account the physical properties of the working fluid was carried out. Good agreement between the calculated and experimental performance characteristics of the main pump HM-3600-230 is illustrated. The relative error of calculations does not exceed 5-8\%.

Originality. The developed object-oriented model of the CP takes into account the vortical circulation processes of the motion of the liquid both at the input and output of the rotor wheel (impeller), and in the interblade space. Also, the model adequately reflects the link between the mechanical and hydraulic subsystem of the pump unit at all load modes, and especially in low-load ones, of its flow duty, taking into account its design parameters and physical properties of the working fluid.

Practical value. The object-oriented model of the CP is easily adapted to modern computer-oriented interactive tools ( 20 -sim, Simulink, Pspice, Dymola, etc.) designed to simulate the modes of operation of mechatronic technical systems, which in turn reveals the way for calculation and optimization of the CP power characteristics as an element of a pumping station.

Keywords: object-oriented modeling, centrifugal pump, mathematical model, liquid circulation, power losses

Introduction. Interactive environment of modern computer simulators: 20-sim, Simulink, Pspice, Dymola, etc. [1], which support the simulation of dynamic modes of complex technical systems with subsystems of different physical nature makes it possible to use already-made unified library of elements (objects). The basis of this approach is the application of objectoriented modeling principles using signal and power domain information to reflect the interactions between the structural objects of the system. Typically, such objects, one of which is a centrifugal pump (CP) of the main oil pipeline, are represented as "black boxes" - multiport elements without proper detail of internal energy exchange processes, in particular energy losses, which depend essentially on the object operation mode. This leads to significant errors in modeling and requires the creation of new CP models that are capable of adequately reflecting complex physical processes throughout the range of its flow rate duties, depending on the structural characteristics of a $\mathrm{CP}$ and physical properties of working fluid.

Literature review. To solve the problem, we use the energy approach, which enables us to establish the balance of powers (instantaneous energies) in subsystems of different physical nature on the basis of conservation of energy law. The system approach strategy usually suggests division of a single complex technical system into five main subsystems [1] at the stage of analysis: electric subsystem (ES), mechanical subsystem of translational motion (MST), mechanical subsystem of rotational motion (MSR), hydraulic subsystem (HS) and heat subsystem (HTS). The energy state of each subsystem at time $t$ is characterized by a pair of conjugated parameters of effort $F_{f}$ and flow $F_{v}$ character, product of which (formula 1) determines the power [1]

$$
N=F_{f} F_{v} .
$$

The most commonly used pairs are: for ES - voltage $U$ and current $I$; for MST - force $F$ and linear velocity $v$; for MSR - torque $M$ and angular velocity $\omega$; for HS - pressure $P=\rho g H$ and volume flow rate $Q$; for HTS - temperature $T$ and heat flow $\varepsilon$. Here, $\rho$ is density of the liquid; $g$ is gravitational acceleration; $H$ is the head of the CP.

(C) Kostyshyn V. S., Yaremak I. I., Kurliak P. O., 2019
The object of the study is a centrifugal pump (CP) - a machine that converts the mechanical energy consumed from the shaft of the drive motor into the hydraulic energy of pipeline fluid. Therefore, from the standpoint of object-oriented modeling, the $\mathrm{CP}$ can be represented as a passive six-pole [2] (Fig. 1) with three power portals $\mathrm{AB}, \mathrm{CD}$ and $\mathrm{EF}$ through which the $\mathrm{CP}$ interacts with neighboring objects.

In particular, the portal $\mathrm{AB}$ reflects the shaft of a $\mathrm{CP}$ impeller, through which the mechanical energy from the drive engine shaft (subsystem MSR) with the conjugated parameters $M$ and $\omega_{r}$ enters to the pump. In turn, the portals CD and EF reflect respectively the input (suction) and output (discharge) pump nozzles, which connect the input and output pipelines (subsystem HS). Through them a fluid moves, the hydraulic energy of which has conjugated parameters $H_{1}, Q_{1}$ and $H_{2}, Q_{2}$ respectively. Normally, when modeling $\mathrm{CP}$, we neglect the hydraulic energy of a liquid, which enters the inlet of the $\mathrm{CP}$ through the portal $\mathrm{EF}\left(\rho g H_{1}=0\right)$, representing the $\mathrm{CP}$ in the form of a passive fourpole with two power portals $\mathrm{AB}$ and $\mathrm{CD}[2]$. In this case, the differential head $H_{R}$ generated by mechanical energy of the drive will be equal to the discharge head $H_{R}=H_{2}-H_{1}$. However, the analysis of literary sources showed that in the computer simulators there are no such object-oriented models of the CP that would allow adequately reflecting the energy connection between the portals $\mathrm{AB}$ and $\mathrm{CD}$ in $\mathrm{CP}$ at all load modes, and especially in the low flow rate ones, taking into account the structural parameters of the $\mathrm{CP}$ and physical properties of the working fluid. Therefore, in order to create such a model [3] it is proposed the use the electrohydrodynamic analogy method based on the isomorphism of mathematical formulas describing physical processes respectively in electric and hydraulic systems.

Normally, analogies are used: electrical voltage - pressure (or head) and electric current - mass (or volume) flow rate (capacity) of liquid. Such an approach made it possible to synthesize "electric" equivalent circuits of hydraulic systems, which can be analyzed using a well-developed apparatus of electrical engineering. On the basis of the electrohydrodynamic analogy method, a complex model of the CP [3] was created. It made it possible for the first time to substantially introduce into consideration active and passive parameters of its 


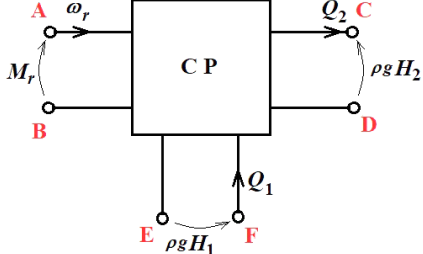

Fig. 1. Representation of a CP in the form of a passive six-pole

equivalent circuit [3], synthesized in a rotating system of coordinates $d, q$, tightly connected to the shaft of the drive motor.

In particular, the concept of "hydromotive force" of the $\mathrm{CP}$ (analogue of electromotive force in electric circuit) as a source of harmonic oscillations of pressure $\rho g H_{0}=$ $=\rho g H_{0} \sin \left(\omega_{P} t\right)$ with internal reactance $x_{t}$, where $\omega_{P}=\pi n / 30$ is angular frequency of oscillations, which is proportional to the frequency of impeller rotation $n ; H_{0}$ is the head of an idealized (without losses and with an infinite number of blades) $\mathrm{CP}$ in an idle mode with a closed valve on the discharge nozzle. On the equivalent circuit all the parameters of the mode are depicted in a complex form - in the form of a generalized image vector (phasor) with parameter underscored from below.

Also, a methodology was proposed for calculating the constant in time and independent on the mode of CP operation active $r$ and reactive (inertial, since the working fluid is considered to be incompressible) $x$ passive parameters of this circuit, which made it possible to obtain good results for constructing head-flow characteristics of the pump $H_{R}=f\left(Q_{R}\right)$ during the changes in the network resistance $r_{\text {load }}=\operatorname{var}$ (the relative error of calculations did not usually exceed 5-8\%). Here, $H_{R}, Q_{R}$ is respectively the value of the head and flow rate at the output of the $\mathrm{CP}$ in a nominal operating mode.

Branches with complex impedance $\underline{Z}_{\Delta H}=r_{\Delta H}+j x_{\Delta H} ; \underline{Z}_{\Delta Q}=$ $=r_{\Delta Q}+j x_{\Delta Q}$ and $\underline{Z}_{m}=r_{m}+j x_{m}$ correspondingly represent the hydraulic, volume and mechanical losses of the $\mathrm{CP}$, while the branches with purely reactive reactances $x_{\mu H}$ and $x_{\mu Q}$ reflect the pressure drop and pump losses caused by the finite number of blades respectively. Here, $j$ is an imaginary unit $(j=\sqrt{-1})$. Active resistances $r_{\Delta H}$ and $r_{\Delta Q}$ simulate irreversible losses (dissipation) of energy into the environment in the form of heat due to the viscous friction forces between the layers of the liquid, while $r_{m}$ represents the thermal losses caused by the forces of impeller disk friction, friction in the bearings and sealing, and $r_{\text {load }}$ is hydraulic resistance of the discharge pipeline. In the general case, resistance is determined by the formula (2) and reflects the physical properties of working fluid, such as its viscosity and density [3]

$$
r=2 \rho v l \frac{\chi^{2}}{S^{3}},
$$

where $v$ is the coefficient of kinematic viscosity; $\chi, S$ are respectively wetted perimeter and the cross-sectional area of section of hydraulic tract of CP with the length $l$.

Inertial reactances $x_{\Delta H}$ and $x_{\Delta Q}$ are caused by inertia forces, which counteract the flow rate changes in the $\mathrm{CP}$ and simulate vortex processes of internal energy transformations (kinetic energy in potential and vice versa). In the general case, inertial reactance is proportional to the density of working fluid and rotational speed of the impeller and is determined by the formula (3) [3]

$$
x=\frac{\pi n}{30} \frac{\rho l}{S} .
$$

Calculation of the equivalent circuit element parameters and CP modes of operation are carried out in the per-unit system, where nominal parameters of the machine are usually chosen as basic parameters. It is enough to set up only two basic parameters - the pressure $H_{b a s}$ and flow rate $Q_{b a s}$, which equal nominal values of the discharge head and flow rate of a $\mathrm{CP}$ respectively. In particular, an important feature should be noted that in the per-unit system (for incompressible liquid), the dimensionless values of pressure and head are equal to each other and are determined by (4)

$$
P_{*}=\frac{\rho g H}{\rho g H_{b a s}}=\frac{H}{H_{b a s}}=H_{*} .
$$

Further, all calculations are carried out in the per-unit system, and therefore the designation " $*$ " is omitted. In this case, one more important feature of the complex model [3] should be noted. It is similar to the model of a synchronous electric machine (Park-Goryev's equation) [4], obtained in a rotary system of coordinates $d, q$, which is tightly connected with the impeller (rotor) of the CP.

This requires the correct combination of such a model of the CP with object-oriented models of other complex system elements, which are usually synthesized in a fixed coordinate system $x, y$ and refer to subsystems of different physical nature. In particular, the shaft of the drive motor is referred to the MSR subsystem, while the discharge pipeline - to the HS subsystem (Fig. 2). That is why at the input of the equivalent circuit of the CP using the inverter $I N$, a source of hydromotive force is introduced - a source of harmonic pressure oscillations $\rho g \underline{H}_{0}$ [3]. A similar reverse operation of returning of the mode's hydraulic parameters which are calculated in the model of the CP (because they vary according to the harmonic sinus law) into the system of fixed coordinates $x, y$, is carried out by entering into the scheme of rectifier RE. Thus, the transition from instantaneous to root mean square (or amplitude) values of the mode parameters is carried out and that is why the pipeline of the HS subsystem is connected to the $\mathrm{CP}$ because of the active impedance of load $r_{\text {load }}$.

In the monograph [3], for the construction of head-flow characteristics of the $\mathrm{CP}$, the root mean square values of heads and flow rates were used, while in the work [5] in BONDGRAPH model of CP a special OSK module was created for the transition from the rotating system of coordinates $d, q$ to the fixed $x, y$ by reading only the amplitude values of the sinusoidal signal.

This feature was not taken into account by an overwhelming number of authors of articles that used the complex model [3] as the basis for constructing their models of elements of pumping stations. In particular, authors of [6] in order to obtain unidirectional electric current in the "electric" model of the CP used a simple element - the m-phased rectifier (diode) [7], explaining its main function as a model of a pump spiral volute [8], and not as a transformer of coordinate systems. Authors [9], like [10, 11], did not mention the rotational coordinate system at all.

In addition, the calculation of the parameters of complex equivalent circuit [3] was based on the empirical knowledge about the CP head in two characteristic operating modes nominal (NOM) and idle operating modes (IM). Therefore, in the scheme for all modes of flow rate duty, a balance of heads was present. However, the balance of power capacities was not fulfilled, which did not allow receiving, in addition to the head-flow characteristics, the whole spectrum of energy characteristics of the $\mathrm{CP}$, in particular characteristics of efficiency and power consumption from the shaft of the drive motor. The presence in the scheme of virtual inertial reactances

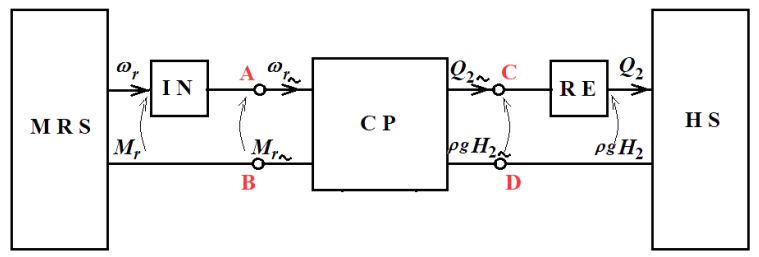

Fig. 2. Implementation of complex model of a CP obtained in the rotary coordinate system $d, q$, which is tightly connected with the impeller of a CP, into general energy scheme of the system between the subsystems MRS and HS (fixed system of coordinates $x, y$ ) 
$x_{u H}$ and $x_{u Q}$ in order to take into account the effect of the finite number of blades on the characteristics of the $\mathrm{CP}$ considerably complicated the solution of the issue of combining the equivalent circuits of the $\mathrm{CP}$, drive motor and pipeline, i.e. the synthesis of a general equivalent circuit of the pumping station.

Another important work in development of the theory of $\mathrm{CP}$ modeling on the basis of the method of electrohydrodynamic analogy became the article [12], in which a refined model of the $\mathrm{CP}$ was proposed. It was based on a modified calculation of mechanical losses in the $\mathrm{CP}$, which reflected the active resistance $r_{m}$, value of which varied proportionally to the square of the flow rate $Q_{R}$. Mechanical power losses were merely algebraically summarized with internal (hydraulic and volume) power losses, which were determined from the classical equivalent circuit of the CP [3], all parameters of which (except for the variables of active resistances $r_{m}$ and $r_{\text {load }}$ ) remained constant, independent on flow rate mode of operation. Good results were obtained in constructing of abovementioned energy characteristics of the $\mathrm{CP}$, but at the same time, the balance of power capacities in equivalent circuit of $\mathrm{CP}$ was violated, which did not allow implementing it in the general equivalent circuit of the pumping station.

Unsolved aspects of the problem. Thus, a relevant task arose of creating such an object-oriented model of the CP, in which there is a simultaneous balance of force (pressures and heads), and flow (capacities) variables in the equivalent circuit of the $\mathrm{CP}$, i. e. the balance of power, which reveals the way to use classical computer simulators (20-sim, Simulink, Pspice, Dymola, etc.) to calculate and optimize the power characteristics of the $\mathrm{CP}$ as an element of a pumping station.

Results. Obviously, the modernized model should take into account the vortex circulation processes of the fluid movement both at the input and output of the driving wheel (impeller), and in the space between the blades, as shown in Fig. 3 for one of the channels between the blades. The indicated processes increase considerably with decreasing liquid flow rate, reaching the maximum in an idle operating mode (closed valve on the outlet) of the $\mathrm{CP}$, when the input and output vortices penetrate deep into the impeller, merging into a single circulating flow inside the space between the blades. Unfortunately, the Euler equation does not allow taking into account the losses of power in this mode, which is called the losses of hydraulic braking [13]. The application of the method of electrohydrodynamic analogy to the scheme of fluid flows in the CP made it possible to synthesize the expanded complex equivalent circuit of the $\mathrm{CP}$, spatially combined with its constructive elements (Fig. 4).

Here, $r_{c}, x_{c}$ are respectively the active resistance and inertial reactance, which are reflecting the energy of the vortex processes of fluid flow at the $i^{\text {th }}$ channel of impeller between the blades with the number of blades $k_{b} ; r_{\text {tong }}$ is active resistance of initial area of the spiral volute (a hole near the "tongue" of the volute); $r_{s v}, x_{s v} ; r_{d i f}, x_{d i f}$ are respectively active resistances and inertial reactances, which are reflecting power losses on the elements of the spiral and the diffuser parts of the volute; $x_{i n}=k_{b} x_{t}$ is internal reactance of the source of hydromotive force $H_{0}$ which is acting between the blades in the $i^{\text {th }}$ channel of impeller. Obviously, all the resistances and reactances in such an equivalent circuit will be variables and will have nonlinear dependence on the flow rate duty $Q_{R}$.

In the model [3], expanded complex equivalent circuit (Fig. 4) by means of equivalence and use of the rotating system of coordinates $d, q$, acquired a simplified shape [3] with constant parameters, which do not depend on the mode of pump operation. However, in this scheme, the inertial reactance disappeared, which now is reflecting the circulation processes in the impeller. Instead, a virtual inertia reactance $x_{\mu Q}$ appeared to take into account the reduction of flow rate of $\mathrm{CP}$ due to the finite number of blades. This led to a disturbance in the balance of power capacities in the scheme.

To settle this situation, we introduce the inertial reactance $x_{\mu Q}$ in the form of a parallel combination of two variables of

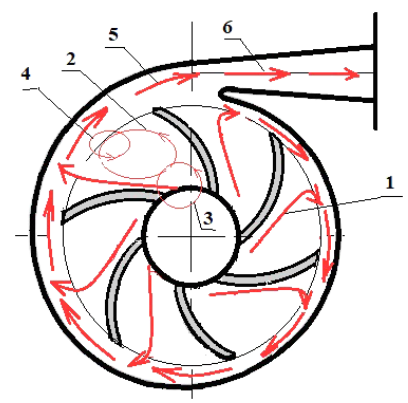

Fig. 3. Scheme of movement of the fluid in an impeller, the spiral volute and the pump diffuser:

1 - main (working) flow in the channel between the blades; 2 circulatory flow in the channel between the blades; 3 - circulation flow at the input of the channel between the blades; 4 - circulation flow at the output of the channel between the blades; 5 - the main stream in the spiral volute; 6 - the main stream in the diffuser

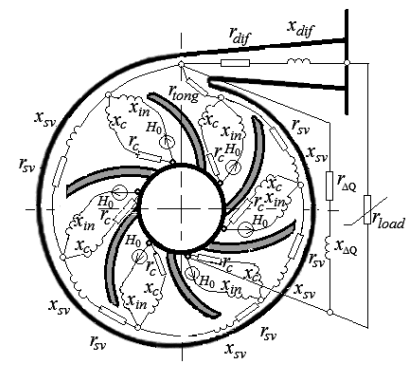

Fig. 4. Expanded complex equivalent circuit of the pump, spatially combined with its constructive elements

inertial reactance $x_{b}$ and $x_{\mu Q v}$ (Fig. 5), the sum of which remains constant (5), equal to $x_{\mu O}$ and we pre-neglect by viscous friction in circulation vortexes of fluid $\left(r_{b} \approx 0\right)$

$$
x_{\mu Q}=\left(\frac{1}{x_{b}}+\frac{1}{x_{\mu Q v}}\right)^{-1}=\text { const. }
$$

Now, in the updated complex equivalent circuit of the CP, the inertial reactance $x_{b}$ will reflect the energy of the vortex processes in the impeller (a balance of power capacities will be performed) and due to the variable reactance $x_{\mu Q v}$, the old scheme remains operative, which has proven itself to adequately reflect the balance of heads in the CP [3]. In addition, mechanical losses in the $\mathrm{CP}$ are conditionally divided into two components: $N_{m}$ - losses of the actual disk friction on the outside of the impeller, mechanical friction in bearings and shaft seals, which are released on the resistance $r_{m}$ and $N_{b}$ - vortex circulating losses at the inlet and outlet and in the space between the blades of an impeller that reflects complex impedance $\underline{Z}_{b}=r_{b}+j x_{b}$.

Although losses are of a hydraulic nature, most authors of the classical works on the theory of pumps [13] classify them as mechanical [14], since they do not belong to the main hydraulic path of the pump, as well as the losses $N_{m}$, which is about $5 \%$ of total power losses in the CP [15]. In the previous stage of equiv-

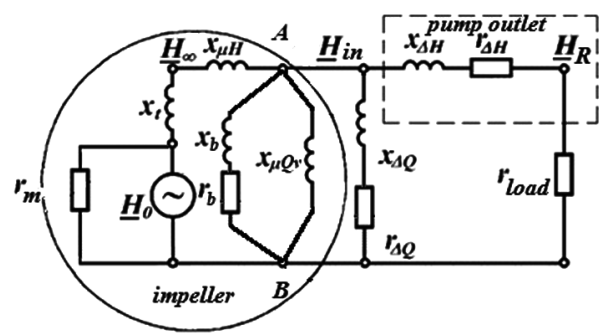

Fig. 5. Equivalent circuit of $C P$ with representation of inertial reactance $x_{\mathrm{u}}$ in the form of parallel conjugation of two variables of inertial reactances $x_{b}$ and $x_{\mu Q v}$ 
alenting of losses $N_{m}$ that are allocated on resistance $r_{m}$, those can be neglected. Then the scheme is easily transformed into a modernized form (Fig. 6), where the equivalent values of hydromotive force $H_{e}$ and inertial reactance $x_{e}$ are determined by $(6,7)$

$$
\begin{aligned}
& H_{e}=H_{o} \frac{x_{e}}{x_{t}+x_{\mu H}}=Q_{C}^{o c} x_{e} ; \\
& x_{e}=\left(\frac{1}{x_{t}+x_{\mu H}}+\frac{1}{x_{\mu Q v}}\right)^{-1} .
\end{aligned}
$$

Performed calculations of equivalent parameters $H_{e}$ and $x_{e}$ for the main pump HM 3600-230 showed little dependence on the change in its flow rate duty $Q_{R}$, since the deviation from their nominal values (at $Q_{R}=1$ ) does not exceed 5-7\%.

In particular, it should be noted that the scheme obtained a three-dimensional image as it illustrates the fact that the leakage of volumetric fluid losses $Q_{\Delta Q}$ through the seal takes place orthogonally to the plane of rotation of the impeller. Only then, after collision with the outer disk surface of the impeller, the fluid will rotate as a solid body at an angular velocity equal to half of angular velocity of the wheel. This motion corresponds to equality of driving moment of friction on the rotating wheel to the braking moment of friction on the wall of the stationary body of CP [3].

In addition, the number of nodes in the scheme is reduced and the portal $\mathrm{AB}$ of input energy, which the $\mathrm{CP}$ consumes from the shaft of the drive motor, is clearly identified. It is obvious that the $H_{e}$ and $x_{e}$ parameters can also be interpreted as the source of this energy, which creates the total internal flow $Q_{C}$. It consists of the main working flow $Q_{R}$, the circulating flow $Q_{b}$ (equal to the sum of vortex flows in the channels between the blades of the impeller) and flow of volumetric losses $Q_{\Delta Q}$.

It is obvious that according to equation (6) $H_{e}$ and $x_{e}$ are interconnected by a constant coefficient of proportionality $Q_{C}^{o c}$, which is equal to the value of the internal flow of the $\mathrm{CP}$ in the mode of "conditional breakdown" of the pipeline (analogue of short circuit mode at electric generator outputs) and is determined by (8)

$$
Q_{C}^{o c}=\frac{H_{e}}{x_{e}}=\frac{H_{o}}{x_{t}+x_{\mu H}}=\text { const. }
$$

Modernized equivalent circuit of the $\mathrm{CP}$ with traced distribution of effort (pressures) and flow (capacities) parameters of modes (Fig. 6) makes it possible to write equation of balance of heads and flow rates in the per-unit system in a complex form (according to Kirchhoff's first and second laws) (9)

$$
\left.\begin{array}{l}
\underline{Q}_{C}-\underline{Q}_{b}-\underline{Q}_{\Delta Q}-\underline{Q}_{R}=0 \\
\underline{H}_{e}-\underline{H}_{i n}-\underline{Q}_{C} j x_{e}=0 \\
\underline{H}_{i n}-\underline{Q}_{b}\left(r_{b}+j x_{b}\right)=0 \\
\underline{H}_{i n}-\underline{Q}_{\Delta Q}\left(r_{\Delta Q}+j x_{\Delta Q}\right)=0 \\
\underline{H}_{i n}-\underline{Q}_{R}\left(r_{\Delta H}+j x_{\Delta H}\right)-\underline{H}_{R}=0
\end{array}\right\}
$$

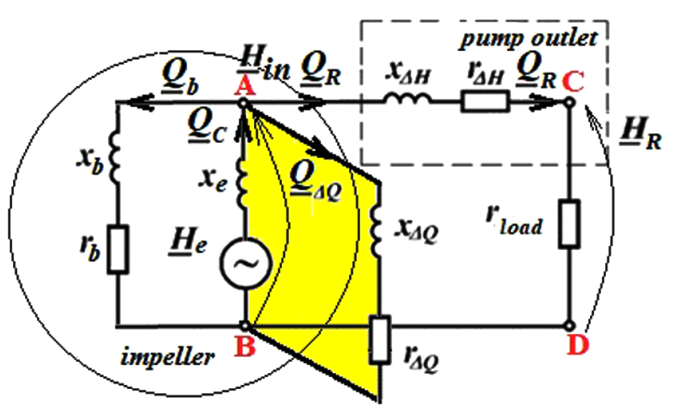

Fig. 6. Modernized complex equivalent circuit of the $C P$ with traced distribution of effort (pressures) and flow (capacities) parameters of modes
Here, $\underline{H}_{\text {in }}$ is the complex value of the head at point A at the output of the impeller (in front of the spiral volute). Along with the balance of heads (pressures), the modernized equivalent circuit reflects the balance of power capacities (Fig. 7). It is obvious that the operating mode of the discharge pipeline, set by the value of load resistance $r_{\text {load }}$, determines the useful hydraulic power at the CP output $N_{e f}=H_{R} Q_{R}$, which, in turn, sets the value of power $N_{C}$ consumed from a shaft of drive motor.

In a complex form, the value $N_{C}$ is determined by (10)

$$
\underline{N}_{C}=\underline{N}_{e f}+\Delta \underline{N},
$$

where $\underline{N}_{e f}$ and $\Delta \underline{N}$ are respectively the complex of useful hydraulic power at the outlet branch and complex of total power losses of the $\mathrm{CP}$, which can be conventionally divided into the following classical components [13] according to equation (11)

$$
\Delta \underline{N}=\underline{N} \Delta_{H}+\underline{N}_{\Delta Q}+\underline{N}_{\Delta M}
$$

Here $\underline{N}_{\Delta H}, \underline{N}_{\Delta Q}, \underline{N}_{\Delta M}$ are respectively complexes of hydraulic, volumetric and mechanical losses of power. Thus, we will assume that total mechanical losses will also include mechanical losses of disk friction, friction in bearings and seals $N_{m}$, and approximately will be equal to circulatory losses $N_{b}$ (12) [13]

$$
\underline{N}_{\Delta M} \approx \underline{N}_{b} \text {. }
$$

On the other hand, the equation 13 is written out of equivalent circuit (Fig. 7)

$$
\underline{N}_{C}=\underline{N}_{\text {in }}+\underline{N}_{\Delta Q}+\underline{N}_{\Delta M},
$$

where $\underline{N}_{i n}$ is the complex of internal hydraulic power of the main hydraulic path of $\mathrm{CP}$, which is equal to the vector sum of useful power at the outlet of CP $\underline{N}_{e f}$ and hydraulic losses in the spiral volute and diffuser $\underline{N}_{\Delta H}(14)$

$$
\underline{N}_{i n}=\underline{N}_{e f}+\underline{N}_{\Delta H}
$$

Obviously, the whole problem is to determine the values of inertial reactance $x_{b}$ depending on operating mode of the CP, which is characterized by its flow rate duty $Q_{R}$. To do this we will use empirical information about $\mathrm{CP}$ operating parameters (flow rates, heads and powers) at two characteristic points - the nominal $\left(Q_{R}=Q_{R}^{\text {nom }}=1, \quad H_{R}=H_{R}^{\text {nom }}=1, \quad N_{C}=N_{C}^{\text {nom }}=1 / \eta_{\Sigma}^{\text {nom }}\right)$ and idle mode $\left(Q_{R}=Q_{R}^{i r}=0, H_{R}=H_{R}^{i r}, N_{C}=N_{C}^{i r}, \quad N_{e f}=0\right)$. Here, $\eta_{\Sigma}^{\text {nom }}$ is the nominal value of energy conversion efficiency of the CP. Conducted computer simulation of operating modes of a series of the main oil pumps of HM type made it possible to propose representation of dependence of $x_{b}$ on $Q_{R}$ in the form of equation (15)

$$
x_{b}=x_{b}^{i r}+\left(x_{b}^{n o m}-x_{b}^{i r}\right) Q_{R}^{3},
$$

where $x_{b}^{\text {nom }}$ and $x_{b}^{i r}$ are respectively values of inertial reactances $x_{b}$ in these modes. In particular, for the idle mode from equivalent circuit we obtain formula (16)

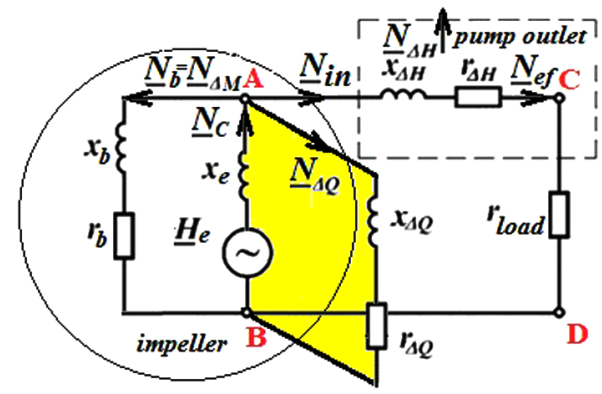

Fig. 7. Modernized complex equivalent circuit of the $C P$ with traced distribution of instantaneous energies (powers) of operating mode 


$$
x_{b}^{i r}=\frac{\left(H_{i n}^{i r}\right)^{2}}{N_{b}^{i r}}=\frac{\left(H_{R}^{i r}\right)^{2}}{N_{b}^{i r}}
$$

where $H_{i n}^{i r}$ is the head of idle mode at the output of the impeller before the spiral volute, which is numerically equal to the head at the outlet of the diffuser $H_{R}^{i r}$, since $Q_{R}^{i r}=0$. Power capacity of mechanical losses developed by fluid circulation flows in the impeller in this mode has the maximum value that can be determined from equation of balance of capacities (17) in a complex form

$$
\underline{N}_{\Delta M}^{i r}=\underline{N}_{b}^{i r}=\underline{N}_{C}^{i r}-\underline{N}_{\Delta Q}^{i r} .
$$

Since power is a product of force (pressure) and flow (flow rate) parameters of the operating mode, equation (17) is in scalar form (18)

$$
\left.\left|H_{R}^{i r}\right| e^{\varphi_{H H}^{i H}}\left|Q_{b}^{i r}\right|\right|^{\varphi_{i}^{i r}}=\left|H_{R}^{i r}\right| e^{\varphi_{H}^{i r}}\left|Q_{C}^{i r}\right| e^{\varphi_{C}^{i r}}-\left|H_{R}^{i r}\right| e^{\varphi_{H H}^{i r}}\left|Q_{\Delta Q}^{i r}\right| e^{\varphi_{\Delta A}^{i r}},
$$

where $\varphi_{H}^{i r}, \varphi_{b}^{i r}, \varphi_{C}^{i r}, \varphi_{\Delta Q}^{i r} ; \quad\left|H_{R}^{i r}\right|,\left|Q_{b}^{i r}\right|,\left|Q_{C}^{i r}\right|,\left|Q_{\Delta Q}^{i r}\right|$ are respectively angles and modules of vectors $\underline{H}_{R}^{i r}, \underline{Q}_{b}^{i r}, \underline{Q}_{C}^{i r}, \underline{Q}_{\Delta Q}^{i r}$ on the complex plane. It is obvious that the right and the left parts of this equation can be reduced by $e^{\varphi_{H}^{i t}}$, which makes it possible to combine the vectors of power capacities and flow rates on the complex plane in the corresponding branches (Fig. 8). In this case, the mechanical losses will feature a pure reactive (inertial) nature, and have an angle $\varphi_{b}^{i r}=90^{\circ}$.

From the vector diagram we obtain (19)

$$
N_{b}^{i r}=\sqrt{\left(N_{C}^{i r}\right)^{2}-\left(N_{\Delta Q a}^{i r}\right)^{2}}-N_{\Delta Q r}^{i r},
$$

where $N_{\Delta Q a}^{i r}$ and $N_{\Delta Q r}^{i r}$ are respectively modules of active and reactive components of the power vector of volumetric losses, which we will determine through the parameters of the CP equivalent circuit according to the system of (20)

$$
\left.\begin{array}{l}
N_{\Delta Q a}^{i r}=N_{\Delta Q}^{i r} \cos \varphi_{\Delta Q}^{i r}=\frac{\left(H_{R}^{i r}\right)^{2}}{r_{\Delta Q}^{2}+x_{\Delta Q}^{2}} r_{\Delta Q} \\
N_{\Delta Q r}^{i r}=N_{\Delta Q}^{i r} \sin \varphi_{\Delta Q}^{i r}=\frac{\left(H_{R}^{i r}\right)^{2}}{r_{\Delta Q}^{2}+x_{\Delta Q}^{2}} x_{\Delta Q}
\end{array}\right\} .
$$

On the other hand, the power consumed from the shaft of the drive motor in the idle mode is determined in the per-unit system by means of the nominal values of energy conversion efficiency and the load angle of CP [3] (21)

$$
N_{C}^{i r}=\frac{\left(1-\gamma_{c}^{\text {nom }} \operatorname{ctg} \gamma_{c}^{\text {nom }}\right)}{\eta_{\Sigma}^{\text {nom }}},
$$

where $\gamma_{c}^{\text {nom }}$ is the nominal value of the load angle of the CP (introduced by analogy with the load angle of a synchronous

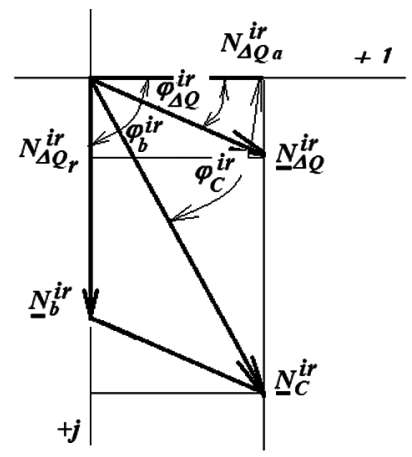

Fig. 8. Vector diagram of powers in idle mode on a complex plane electric machine), which in the first approximation is related to the specific speed coefficient $n_{s}$ of CP by (22) [3]

$$
\gamma_{c}^{n o m} \approx 0.475\left(1+\frac{n_{s}}{100}\right) .
$$

Calculations were conducted for a series of main oil pumps of HM type, catalog nominal parameters and parameters of equivalent circuit of which are shown in [3]. The results of calculations of inertial reactances are given in Table 1.

Similarly we determine the value of inertial reactance $x_{b}^{\text {nom }}$ in the nominal mode of operation by (23)

$$
x_{b}^{\text {nom }}=\frac{H_{\text {in }}^{\text {nom }}}{Q_{b}^{\text {nom }}},
$$

where $H_{\text {in }}^{\text {nom }}$ is the nominal value of the head at the output of impeller at the beginning of the spiral volute, which is determined in the per-unit system through the nominal value of hydraulic energy conversion efficiency of CP $\eta_{H}^{n o m}$ by equation $H_{\text {in }}^{\text {nom }}=1 / \eta_{H}^{\text {nom }}$.

To find the nominal value of circulating flow rate $Q_{b}^{\text {nom }}$, we write the equation of the balance of flow rates in the $\mathrm{CP}$ in a complex form according to equation (24)

$$
\underline{Q}_{C}^{n o m}=\underline{Q}_{R}^{n o m}+\underline{Q}_{\Delta Q}^{n o m}+\underline{Q}_{b}^{n o m},
$$

to which a vector diagram corresponds (Fig. 9).

On the basis of a vector diagram, we write down two scalar equations of the balance of active and reactive components of flow rates (projections of vectors on coordinate axis of the complex plane), taking into account that in the per-unit system $Q_{R}^{\text {nom }}=1(25)$

$$
\left.\begin{array}{l}
Q_{C}^{\text {nom }} \cos \varphi_{C}^{\text {nom }}=1+Q_{\Delta Q}^{\text {nom }} \cos \varphi_{\Delta Q}^{\text {nom }}+Q_{b}^{\text {nom }} \cos \varphi_{b}^{\text {nom }} \\
Q_{C}^{\text {nom }} \sin \varphi_{C}^{\text {nom }}=0+Q_{\Delta Q}^{\text {nom }} \sin \varphi_{\Delta Q}^{\text {nom }}+Q_{b}^{\text {nom }} \sin \varphi_{b}^{\text {nom }}
\end{array}\right\} .
$$

Taking into account that the values of the angles of inclination vectors of flow rates to the axis of the real component can be estimated with neglected thermal losses due to the friction forces in the spiral volute and the diffuser $\left(r_{\Delta H} \approx 0\right)(26)$

Table 1

Calculated parameter values for $\gamma_{c}^{n o m}, x_{b}^{i r}, x_{b}^{\text {nom }}$ for main pumps of HM type

\begin{tabular}{|c|l|c|c|c|c|}
\hline № & Model of the pump & $n_{S}$ & $\gamma_{c}^{\text {nom }}$ & $x_{b}^{\text {ir }}$ & $x_{b}^{\text {nom }}$ \\
\hline 1 & HM-1250-260 & 70 & 0.803 & 5.246 & 5.748 \\
\hline 2 & HM-2500-230 & 109 & 0.899 & 4.421 & 8.944 \\
\hline 3 & HM-3600-230 & 131 & 1.085 & 3.300 & 9.590 \\
\hline 4 & HM-5000-210 & 165 & 1.260 & 2.713 & 8.356 \\
\hline 5 & HM-7000-210 & 195 & 1.380 & 2.449 & 9.756 \\
\hline 6 & HM-10000-210 & 233 & 1.546 & .227 & 10.949 \\
\hline
\end{tabular}

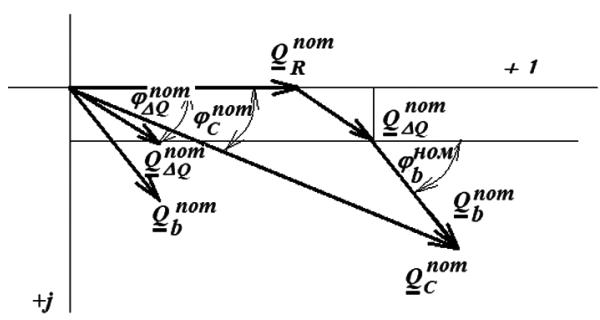

Fig. 9. Vector diagram of flow rates in the nominal mode on a complex plane 


$$
\left.\begin{array}{l}
\varphi_{b}^{\text {nom }} \approx \frac{\pi}{2}-\operatorname{arctg}\left(x_{\Delta H}\right) \\
\varphi_{\Delta Q}^{\text {nom }} \approx \operatorname{arctg}\left(\frac{x_{\Delta Q}}{r_{\Delta Q}}\right)-\operatorname{arctg}\left(x_{\Delta H}\right)
\end{array}\right\} .
$$

In addition, nominal values of flow rates are represented as a system of equations (27)

$$
\left.\begin{array}{l}
Q_{R}^{\text {nom }}=1 \\
Q_{b}^{\text {nom }}=\frac{H_{\text {in }}^{\text {nom }}}{x_{b}^{\text {nom }}} \\
Q_{\Delta Q}^{\text {nom }}=\frac{H_{\text {in }}^{\text {nom }}}{\sqrt{\left(x_{\Delta Q}^{\text {nom }}\right)^{2}+\left(r_{\Delta Q}^{\text {nom }}\right)^{2}}}
\end{array}\right\} .
$$

Simultaneous consideration of equations (16-27) allows us to calculate the unknown value of inertial reactance $x_{b}^{\text {nom }}$, and the results of similar calculations for a series of oil mainline pumps of HM type are given in Table 1.

The graph of dependence of reactance $x_{b}$ on the flow rate$Q_{R}$, calculated by (15) for the pump HM 3600-210, is shown in Fig. 10. It confirms the conclusion obtained in [12] that the deviation of the operating mode from the nominal one is accompanied by a change in mechanical losses of power under parabolic law of the second order, which determines the corresponding change of reactance $x_{b}$.

Also, Fig. 11 represents graphs of modifying of modules of flow (capacities $Q_{C}, Q_{b}, Q_{R}$ and $Q_{\Delta Q}$ ) and effort (head $\underline{H}_{i n}$ ) parameters of the CP operating mode, depending on the flow rate $Q_{R}$.

Separately, Fig. 12 demonstrates in the per-unit system dependence on $Q_{R}$ of power modules $\underline{N}_{C}, \underline{N}_{e}, \underline{N}_{\Delta Q}$ and $\underline{N}_{b}$ of the main pump HM 3600-230. It is obvious that in the low loading mode almost all the power consumed from the shaft of the drive motor goes to cover mechanical losses caused by circulating flow $Q_{b}$. The results of all calculations of power parameters of the modes for the main pump HM 3600-230 are also given in Table 2. Modernized equivalent circuit of the CP (Fig. 6) makes it possible to easily calculate the energy conversion efficiency coefficients of the CP. So the hydraulic energy conversion efficiency is determined by (28)

$$
\eta_{H}=\frac{H_{R}}{H_{\text {in }}} .
$$

The volumetric energy conversion efficiency coefficient is calculated by (29)

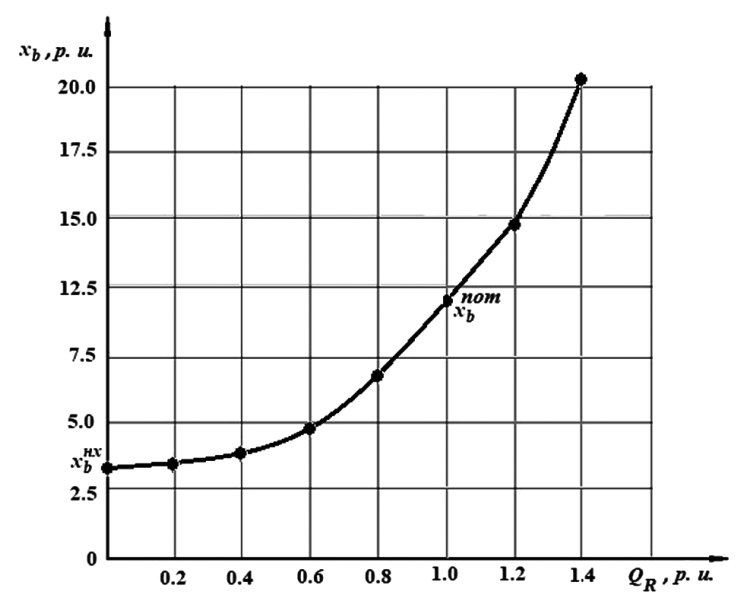

Fig. 10. Graph of dependence of reactance $x_{b}$ on the flow rate $Q_{R}$, calculated for the pump HM 3600-210

$$
\eta_{Q}=\frac{Q_{R}}{Q_{i n}}=\frac{Q_{R}}{Q_{R}+Q_{\Delta Q}},
$$

and the mechanical energy conversion efficiency coefficient is calculated by (30)

$$
\eta_{M}=\frac{N_{\text {in }}}{N_{C}}=\frac{Q_{R}+Q_{\Delta Q}}{Q_{C}} .
$$

It is known that the full energy conversion efficiency coefficient is calculated as the product of three above-mentioned energy conversion efficiency coefficients [14] by (31)

$$
\eta_{\Sigma}=\eta_{H} \eta_{Q} \eta_{M}
$$

Dependencies of the indicated energy conversion efficiency coefficients on the flow rate $Q_{R}$ for the pump HM 3600-230 are shown in Fig. 13.

Adequacy of the modeling confirms the good matching of the operating characteristic of the main pump NM 3600-230 calculated and obtained in experiments (Figs. 14, 15).

Conclusions.

1.The work solved an actual task of creating on the basis of method of electrohydrodynamic analogy of object-oriented model of CP, in which there is a simultaneous balance between the effort (pressure and head) and flow (capaticy) parameters in the modernized complex equivalent circuit of the $\mathrm{CP}$, meaning power balance, which reveals the way for using

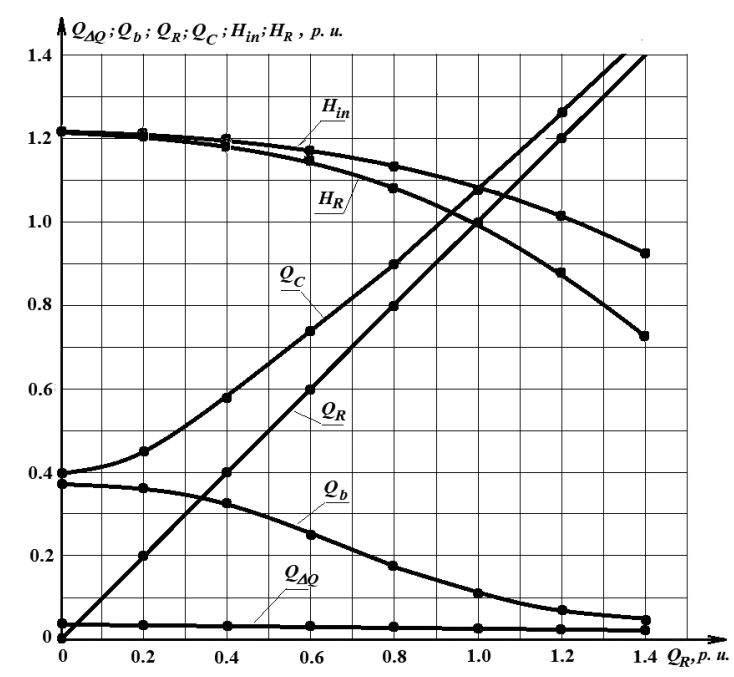

Fig. 11. Graphs of changing of modules of flow (capacities $Q_{C}$, $Q_{b}, Q_{R}$ and $Q \Delta_{Q}$ ) and effort (head $\underline{H}_{\text {in }}$ ) parameters of operating mode, depending on the flow rate $Q_{R}$ for the main pump HM 3600-230

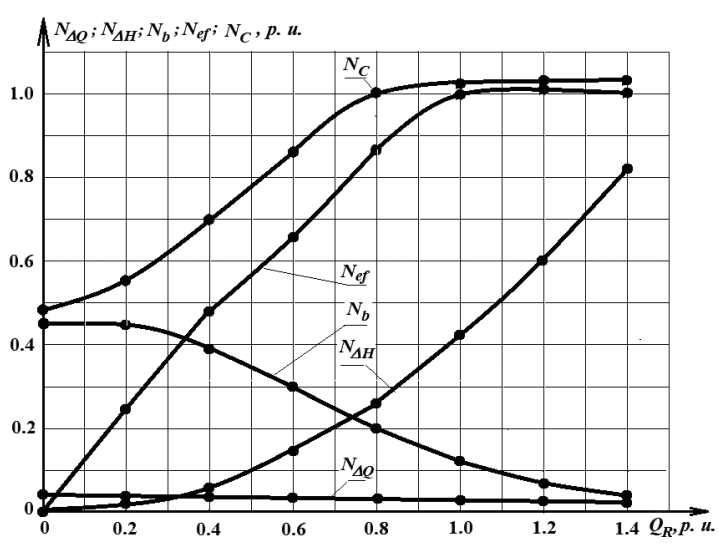

Fig. 12. Dependence of modules of power $\underline{N}_{C}, \underline{N}_{e}, \underline{N}_{\Delta Q}$ and $\underline{N}_{b}$ for main pump HM 3600-230 on $Q_{R}$ 
Calculated values of energy parameters of the mode for the main pump HM 3600-230

\begin{tabular}{|c|c|c|c|c|c|c|c|c|c|c|c|c|c|c|}
\hline$Q_{R}$ & $Q_{\Delta Q}$ & $Q_{b}$ & $Q_{C}$ & $H_{i n}$ & $N_{\Delta q}$ & $N_{b}$ & $N_{c}$ & $N_{e f}$ & $\eta_{Q}$ & $\eta_{H}$ & $\eta_{\mu}$ & $\eta_{\Sigma}$ & $H_{e}$ & $x_{e}$ \\
\hline 0.0 & 0.032 & 0.370 & 0.393 & 1.222 & 0.039 & 0.453 & 0.480 & 0.000 & 0.000 & 1.000 & 0.081 & 0.000 & 1.344 & 0.311 \\
\hline 0.1 & 0.032 & 0.369 & 0.413 & 1.220 & 0.039 & 0.451 & 0.504 & 0.122 & 0.797 & 0.999 & 0.304 & 0.242 & 1.343 & 0.311 \\
\hline 0.2 & 0.032 & 0.363 & 0.456 & 1.216 & 0.038 & 0.442 & 0.555 & 0.243 & 0.888 & 0.998 & 0.494 & 0.437 & 1.342 & 0.310 \\
\hline 0.3 & 0.031 & 0.349 & 0.514 & 1.210 & 0.038 & 0.422 & 0.622 & 0.361 & 0.922 & 0.994 & 0.633 & 0.580 & 1.338 & 0.309 \\
\hline 0.4 & 0.031 & 0.324 & 0.580 & 1.201 & 0.037 & 0.389 & 0.696 & 0.475 & 0.939 & 0.990 & 0.734 & 0.683 & 1.330 & 0.307 \\
\hline 0.5 & 0.031 & 0.291 & 0.652 & 1.189 & 0.037 & 0.346 & 0.775 & 0.585 & 0.950 & 0.984 & 0.807 & 0.755 & 1.320 & 0.305 \\
\hline 0.6 & 0.030 & 0.252 & 0.728 & 1.174 & 0.036 & 0.296 & 0.855 & 0.688 & 0.958 & 0.977 & 0.860 & 0.804 & 1.308 & 0.302 \\
\hline 0.7 & 0.030 & 0.212 & 0.810 & 1.156 & 0.035 & 0.245 & 0.936 & 0.783 & 0.964 & 0.967 & 0.897 & 0.836 & 1.296 & 0.299 \\
\hline 0.8 & 0.029 & 0.174 & 0.896 & 1.135 & 0.033 & 0.198 & 1.017 & 0.868 & 0.968 & 0.955 & 0.923 & 0.853 & 1.284 & 0.297 \\
\hline 0.9 & 0.029 & 0.141 & 0.985 & 1.111 & 0.032 & 0.157 & 1.094 & 0.941 & 0.971 & 0.941 & 0.941 & 0.860 & 1.274 & 0.294 \\
\hline 1.0 & 0.028 & 0.113 & 1.076 & 1.084 & 0.030 & 0.123 & 1.166 & 1.000 & 0.974 & 0.923 & 0.954 & 0.858 & 1.266 & 0.293 \\
\hline 1.1 & 0.027 & 0.09 & 1.169 & 1.053 & 0.029 & 0.095 & 1.231 & 1.042 & 0.977 & 0.900 & 0.963 & 0.847 & 1.259 & 0.291 \\
\hline 1.2 & 0.026 & 0.072 & 1.263 & 1.018 & 0.027 & 0.073 & 1.285 & 1.063 & 0.979 & 0.870 & 0.971 & 0.827 & 1.253 & 0.290 \\
\hline 1.3 & 0.025 & 0.057 & 1.358 & 1.978 & 0.025 & 0.056 & 1.328 & 1.058 & 0.981 & 0.832 & 0.976 & 0.797 & 1.249 & 0.289 \\
\hline 1.4 & 0.024 & 0.045 & 1.453 & 1.934 & 0.023 & 0.042 & 1.357 & 1.020 & 0.983 & 0.780 & 0.980 & 0.751 & 1.245 & 0.288 \\
\hline
\end{tabular}

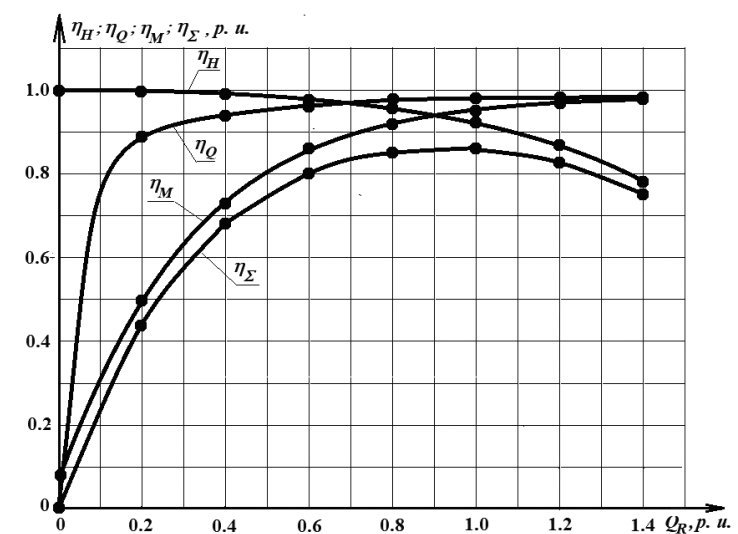

Fig. 13. Dependence of energy conversion efficiency coefficients $\eta_{\Sigma}, \eta_{H}, \eta_{Q}, \eta_{M}$ for the main pump HM 3600-230 on the $Q_{R}$

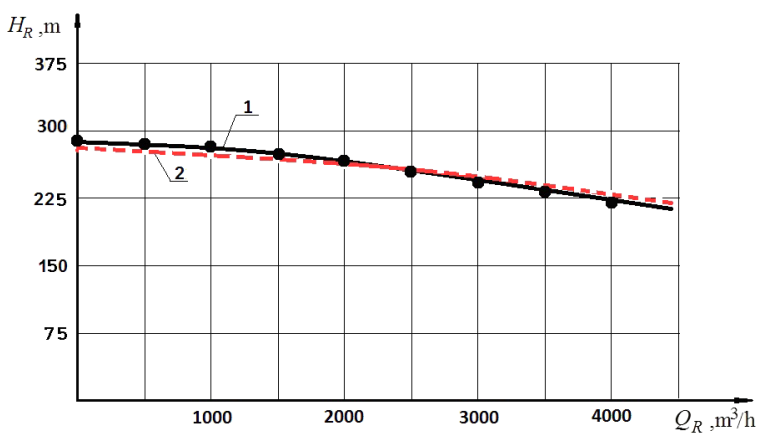

Fig. 14. Dependence of head characteristics $H_{R}$ on the flow rate $Q_{R}$ of the main pump HM 3600-230, calculated with the help of the modernized equivalent circuit of the CP (curve 1) and obtained experimentally (curve 2)

computer simulators to calculate and optimize the energy performance of the $\mathrm{CP}$ as an element of a pumping station.

2. New model takes into account the vortex circulation processes of the fluid flow both at the input and output of the impeller and in the space between the blades, which made it possible to theoretically calculate the performance characteristics of the $\mathrm{CP}$ according to its catalog data over the entire

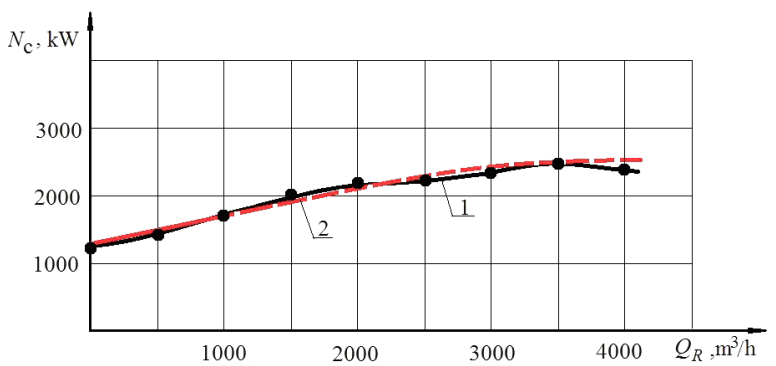

Fig. 15. Dependence of characteristics of power consumption $N_{C}$ on the flow rate $Q_{R}$ of the main pump HM 3600-230, calculated with the help of modernized scheme of replacement of the $C P$ (curve 1) and obtained experimentally (curve 2)

interval of the change in flow rate duty taking into account physical properties of working fluid.

3. A good match of calculated and experimental operating characteristics of the main pump HM 3600-230 is illustrated. Relative error of calculations does not exceed 5-8\%.

\section{References.}

1. Damic, V., \& Montgomery, J. (2015). Mechatronics by Bond Graphs An Object-Oriented Approach to Modelling and Simulation $2^{\text {nd }}$ ed., Springer-Verlag Berlin Heidelberg. ISBN-13: 9783662490020, ISBN-10: 3662490021.

2. Gevorkov, L., Rassõlkin, A., Kallaste, A., \& Vaimann, T. (2018). Simulink based model for flow control of a centrifugal pumping system. $25^{\text {th }}$ International Workshop on Electric Drives: Optimization in Control of Electric Drives (IWED), Moscow, Russia, Jan. 2018, (pp. 1-4). https://doi. org/10.1109/IWED.2018.8321399.

3. Kostyshyn, V.S. (2004). Simulation modes of centrifugal pumps based on electrohydraulic analogy. The electronic scientific journal "Oil and Gas Business", (1), 1-6.

4. Pivnyak, G. G., Zhezhelenko, I. V., Papaika, Y.A., \& Nesen, L. I. (2016). Transients in Electric Power Supply Systems ( $5^{\text {th }}$ ed.) Trans Tech Publications Ltd, Switzerland. ISBN10: 3038357731 .

5. Kostyshyn, V.S., \& Kurliak, P. O. (2012). Investigation of dynamical operating modes of electric drive centrifugal pumping units with the help of their computer-oriented Bond Graph models. Bulletin of the Vinnitsa Polytechnic Institute, (2), 148-153. 
6. Boiko, V. S., \& Sotnyk, M. I. (2013). Adequacy of electrical modeling of work processes in a centrifugal pump. Technical electrodynamics, (5), 90-96.

7. Boiko, V. S., \& Sotnyk, M. I. (2015). Electrical modeling of workflows in electrical systems of water supply retworks. Journal of Engineering Sciences, 2(2), 1-12.

8. Boiko, V. S., \& Sotnyk, M. I. (2014). Electromagnetic process in an electric model of a centrifugal pump. Naukovyi Visnyk Natsionalnoho Hirnychoho Universytetu, (3), 91-98.

9. Lysenko, O.A. (2014). Energy saving modes of centrifugal pumps installations with asynchronous engines. Bulletin of the Tomsk Polytechnic University, 325(4), 133-141.

10. Lysyak, V. G., Shelekh, Y. L., \& Sabat, M. B. (2017). The steady-state modes of the complex "electrical supply system pumping station". Electrotechnic and computer systems, 25(101), 34-43.

11. Korenkova, T.V., \& Kovalchuk, V. G. (2013). Identification of parameters of pumping complexes using the energy criterion. Engineering and educational technologies in electrical engineering and computer systems, 1(1), 14-20.

12. Kostyshyn, V.S., \& Kurliak, P. O. (2015). Simulation of performance characteristics of centrifugal pumps by the electro-hydrodynamic analogy method. Journal of Hydrocarbon Power Engineering, 2(1), 24-31.

13. Sayed Ahmed Imran Bellary, \& Abdus Samad (2015). Numerical Analysis of Centrifugal Impeller for Different Viscous Liquids. International Journal of Fluid Machinery and Systems, 8(1), 36-45. https://doi.org/10.5293/IJFMS.2015.8.1.036.

14. Ravi Shastri, Anjani Kumar Singh, \& Manish Kumar Singh (2014). Analysis About Losses of Centrifugal Pump by Matlab. International Journal of Computational Engineering Research (IJCER), 04(9), 12-22.

15. Volk, M. (2013). Pump Characteristics and Applications ( $3^{\text {rd }}$ Ed.). CRC Press.

\section{Створення об'єктно-орієнтованої моделі відцентрового насоса на основі методу електрогідродинамічної аналогії}

\section{В. С. Костишин, І. І.Яремак, П. О. Курляк}

Івано-Франківський національний технічний університет нафти і газу, м. Івано-Франківськ, Україна, е-таil: yaremak_iryna@ukr.net

Мета. Розроблення об'єктно-орієнтованої моделі відцентрового насоса (ВН), що відображала би конструктивні особливості будови та процеси у ньому, а також одночасний баланс як силових (напорів і тисків), так і швидкісних (витрат) параметрів, тобто баланс потужностей.

Методика. Застосування методу електрогідродинамічної аналогії до схеми потоків рідини у відцентровому насосі дало змогу синтезувати розгорнуту комплексну схему заміщення ВН, просторово суміщену з його конструктивними елементами.

Результати. Проведено теоретичний розрахунок робочих характеристик ВН за його каталоговими даними на всьому інтервалі зміни витратного навантаження 3 урахуванням фізичних властивостей робочої рідини. Проілюстровано хороший збіг розрахункових та отриманих експериментально робочих характеристик помпи НМ 3600-230. Відносна похибка розрахунків не перевищує 5-8\%.

Наукова новизна. Розроблена об’єктно-орієнтована модель ВН ураховує вихрові циркуляційні процеси руху рідини як на вході й виході робочого колеса (імпелера), так і в міжлопатевому просторі. Також модель адекватно відображає енергетичний зв'язок між механічною й гідравлічною підсистемою насосного агрегату на всіх, а особливо на маловитратних режимах його навантаження, із урахуванням його конструктивних параметрів і фізичних властивостей робочої рідини.

Практична значимість. Розроблена об'єктно-орієнтована модель відцентрового насоса легко адаптується до сучасних комп'ютерно-орієнтованих інтерактивних інструментів (20-sim, Simulink, Pspice, Dymola тощо), призначених для моделювання режимів роботи мехатронних технічних систем, а це, у свою чергу, відкриває шлях для розрахунку та оптимізації енергетичних характеристик відцентрового насоса як елемента насосної станції.

Ключові слова: об'єктно-орієнтоване моделювання, відиентровий насос, математична модель, циркуляція рідини, втрати потужності

\section{Создание объектно-ориентированной модели центробежного насоса на основе метода электрогидродинамической аналогии}

\section{В. С. Костышин, И. И. Яремак, П. О. Курляк}

Ивано-Франковский национальный технический университет нефти и газа, г. Ивано-Франковск, Украина, e-mail: yaremak_iryna@ukr.net

Цель. Разработка объектно-ориентированной модели центробежного насоса (ЦН), которая будет отражать конструктивные особенности строения и процессы в нем, а также одновременный баланс как силовых (напоров давлений), так и скоростных (расходов) параметров, то есть баланс мошностей.

Методика. Применение метода электрогидродинамической аналогии к схеме потоков жидкости в центробежном насосе позволило синтезировать развернутую комплексную схему замещения ЦН, пространственно совмещенную с его конструктивными элементами.

Результаты. Проведен теоретический расчет рабочих характеристик ЦН по его каталоговым данным на всем интервале изменения расходной нагрузки с учетом физических свойств рабочей жидкости. Проиллюстрировано хорошее совпадение расчетных и полученных экспериментально рабочих характеристик магистрального насоса НМ 3600-230. Относительная погрешность расчетов не превышает 5-8 \%.

Научная новизна. Разработанная объектно-ориентированная модель ЦН учитывает вихревые циркуляционные процессы движения жидкости как на входе и выходе рабочего колеса (импеллера), так и в межлопастном пространстве. Также модель адекватно отражает энергетическую связь между механической и гидравлической подсистемой насосного агрегата на всех, а особенно на малозатратных режимах его нагрузки, с учетом его конструктивных параметров и физических свойств рабочей жидкости.

Практическая значимость. Разработанная объектноориентированная модель центробежного насоса легко адаптируется к современным компьютерно-ориентированным интерактивным инструментам (20-sim, Simulink, Pspice, Dymola и т.д.), предназначенным для моделирования режимов работы мехатронных технических систем, а это, в свою очередь, открывает путь для расчета и оптимизации энергетических характеристик центробежного насоса как элемента насосной станщии.

Ключевые слова: объектно-ориентированное моделирование, центробежный насос, математическая модель, циркуляция жидкости, потери мощности

Recommended for publication by B. V. Kopei, Doctor of Technical Sciences. The manuscript was submitted 15.03.19. 